REVIEW

\title{
Management of newly diagnosed diabetes: home or hospital?
}

\author{
L Lowes, J W Gregory
}

Arch Dis Child 2004;89:934-937. doi: 10.1136/adc.2003.035949

Type 1 diabetes is one of the most common chronic childhood disorders, occurring with increasing frequency. Diabetes management involves the child and family learning how to inject insulin and monitor blood glucose, and adhere to a diet containing healthy food choices. Medical interventions necessary to stabilise newly diagnosed diabetes depend upon the clinical condition of the child at presentation. Hospital admission is necessary if intravenous therapy is required to correct dehydration, electrolyte imbalance, and ketoacidosis, with progression to oral fluids and subcutaneous insulin administration as the child's condition improves. If the child is mildly to moderately symptomatic and clinically well, subcutaneous insulin and oral diet and fluids may be begun from the time of diagnosis, and stabilisation at diagnosis does not necessarily require hospital admission. This article reviews the evidence concerning hospital or home based treatment at diagnosis for children with type 1 diabetes. The Cardiff approach to home management is briefly described, and the benefits and disadvantages of different approaches to initial management are discussed.

See end of article for authors' affiliations

Correspondence to: Lesley M Lowes, Research Fellow/Practioner (Paediatric Diabetes) Department of Child" Health, University Hospital of Wales, Heath Park, Cardiff CF14 4XW, ÚK Lowes@cardiff.ac.uk

Accepted 4 March 2004
$\mathrm{T}$ ype 1 diabetes is one of the most common chronic childhood disorders, ${ }^{1}$ occurring with increasing frequency. ${ }^{2-4}$ A relative insufficiency of insulin at diagnosis results in hyperglycaemia, polyuria, polydipsia, lethargy, and weight loss. If untreated, severe fluid, electrolyte, and acid-base disturbances will lead to vomiting, dehydration, coma, and death. ${ }^{5}$ Diabetes management involves the child and family learning how to inject insulin and monitor blood glucose, and adhering to a diet containing healthy food choices. Medical interventions necessary to stabilise newly diagnosed diabetes depend upon the clinical condition of the child at presentation. Hospital admission is necessary if intravenous therapy is required to correct dehydration, electrolyte imbalance, and ketoacidosis (DKA), with progression to oral fluids and subcutaneous insulin administration as the child's condition improves. If the child is mildly to moderately symptomatic and clinically well, subcutaneous insulin and oral diet and fluids may be begun from diagnosis, ${ }^{5}$ and stabilisation at diagnosis does not necessarily require hospital admission. $^{6-11}$
In this paper, we review the evidence about hospital versus home based treatment at diagnosis for children with type 1 diabetes. We briefly describe the Cardiff approach to home management and discuss the benefits and disadvantages of different approaches to initial management.

\section{EVIDENCE BASED PRACTICE}

There is little evidence to support either initial hospital admission or initial home management at the time of diagnosis of type 1 diabetes. ${ }^{12}{ }^{13}$ Most studies investigating home management have been retrospective, have relied on patient/ family self report and review of medical records, and have focused on the child's physiological health outcome. ${ }^{13}$ Some knowledge has accrued about outcomes such as readmission rates, ${ }^{8} 101415$ metabolic control, ${ }^{10}{ }^{15-17}$ and cost-effectiveness. ${ }^{8}{ }^{14}{ }^{17-21}$ Findings from these studies support outpatient care from diagnosis as a safe and effective alternative to hospital admission for children who are clinically well at diagnosis. Surprisingly, though, considering the predominance of retrospective studies, little account has been taken of any biases that may affect outcomes in patient groups treated at home or in hospital from the time of diagnosis, such as the severity of metabolic illness at presentation or changes in management over time in historical comparisons, rendering most conclusions uninterpretable. There are also differing interpretations of home management, ranging from complete avoidance of hospital admission ${ }^{67}$ to 27 hours in hospital. ${ }^{21}$

Studies that include an examination of costeffectiveness $^{8}$ 14 17-21 $^{\text {17. }}$ have been undertaken mainly in the USA and Canada. Findings suggest a cost benefit from outpatient management or, at the very least, no significant difference in costs between home and hospital management. ${ }^{21}$ However, other outcomes need to be taken into account. Home management is thought to reduce subsequent readmissions, ${ }^{10} 1119$ which would consequently reduce costs and bed occupancy. Home management is also believed to result in improved glycaemic control ${ }^{14}{ }^{1921}$ which, if sustained, has positive cost implications in relation to the reduced risk of diabetes related complications in later life. ${ }^{22}$ These issues need to be examined over time, not merely to assess cost-effectiveness, but more importantly, to determine the effect of home management on the long term health and wellbeing of patients.

Abbreviations: DKA, dehydration, electrolyte imbalance, and ketoacidosis; PDSN, paediatric diabetes specialist nurse; WTE, whole time equivalent 
Little is known about the psychosocial or behavioural outcomes of outpatient management of childhood diabetes. ${ }^{13}$ The period immediately following a diagnosis is an anxious and distressing time for the whole family. ${ }^{23}$ Parents often find it difficult to come to terms with the diagnosis, which they may view as the end of "normal" health and a familiar lifestyle. ${ }^{24} 25$ The shock and distress experienced by parents when their child is diagnosed with diabetes is described in several studies. ${ }^{23}{ }^{26-28}$ These parents are believed to experience a grief response similar to that normally associated with bereavement, and the process of adjustment and adaptation by parents is often likened to mourning. ${ }^{25}{ }^{29-31}$

\section{A WORLDWIDE PERSPECTIVE}

Worldwide, many centres continue to admit newly diagnosed children, with considerable variation in the length of stay. ${ }^{32}{ }^{33}$ The average length of hospital admission in Finland, ${ }^{32}$ Japan, ${ }^{27}$ and Sweden ${ }^{33}$ is around three weeks. Studies have shown, though, that reducing the length of stay from a mean of 23 days to nine days has no effect on metabolic or psychosocial outcomes with a cost saving of $36 \%,{ }^{32}$ and that early discharge to a training apartment improves information and attention received and the emotional response to treatment. ${ }^{33}$ Indeed, several centres, particularly in America and Canada, have eliminated unnecessary hospital admissions with no adverse effects. ${ }^{6-8} 1419213435$

\section{MANAGEMENT IN THE UNITED KINGDOM}

Historically, in the United Kingdom children with diabetes have been admitted to hospital routinely at diagnosis. For example, $96 \%$ of children under 15 years of age diagnosed in 1988 were admitted to hospital at diagnosis. ${ }^{36}$ Hospital admission would have been necessary for some of these children because of their clinical condition. However, a lack of local resources for home care appears to have contributed to this high admission rate because a 1988 survey of 360 paediatricians in the UK established that although 314 (87\%) admitted more than $80 \%$ of all newly diagnosed children, 170 $(47 \%)$ would change this policy if community facilities were improved. ${ }^{37}$ Since the time when outpatient management of children with newly diagnosed diabetes was introduced in Leicestershire in the early $1950 \mathrm{~s},{ }^{38}$ there has been an increasing trend towards this approach to care across the UK. ${ }^{9} 1012$ 39-41

\section{THE CARDIFF EXPERIENCE}

The established paediatric diabetes team in Cardiff has until recently consisted of a consultant paediatric endocrinologist, a specialist registrar, two paediatric diabetes specialist nurses (PDSNs) (1.5 WTE), a paediatric dietician (0.1 WTE), and a consultant clinical child psychologist (0.1 WTE). The Cardiff service covers 250 square miles, comprising a predominantly urban geographical area with rural outreaches that has an approximate population of 128000 children under 18 years of age. Home management was introduced in October 1995 following the employment of a full time PDSN. At that time, 154 children aged 18 years or less attended the paediatric diabetes clinic, but the numbers currently total 211 children aged 17 years or less. From 1 January 1995 to 31 December 2003, there have been 240 newly diagnosed children ( 15 to 33 new cases annually). One hundred and ninety (79\%) were clinically well (blood pH $>7.29$ ) at presentation, 143 (75\%) of whom were home managed.

Most newly diagnosed children were referred by their GP to the paediatric assessment unit at the University Hospital of Wales. Children who were not ketoacidotic were started on twice daily injections of mixed insulin, usually receiving their first injection at home with PDSN support. PDSNs visited families at home twice a day (when insulin was due) for the first few days after diagnosis to provide support and education about the practicalities of diabetes management. They provided diabetes education to school and nursery staff. A domiciliary paediatric dietetic service is not available in Cardiff. Children diagnosed during office hours saw the paediatric dietician before discharge. Otherwise, PDSNs gave initial basic dietetic advice, and the paediatric dietician provided continuing education on an outpatient basis. Families could access advice out of office hours through an on-call mobile phone held by members of the paediatric diabetes team or, alternatively, could contact staff on the paediatric medical ward.

\section{DISCUSSION}

There are four approaches to the initial management of children with newly diagnosed diabetes: total home management; ambulatory care (home from diagnosis with initial injections and education delivered in the hospital setting); a short admission (less than four days); and a long admission (four days to three weeks). There is a concern that home management is being viewed as the gold standard model for newly diagnosed children who present clinically well. ${ }^{12}$ However, there is insufficient evidence about the relative effectiveness of the various approaches. The current answer to the home versus hospital debate concerns flexible working by a multidisciplinary team, who select a model after consideration of all relevant factors. For instance, although home management has been successfully implemented in Cardiff, this approach is clearly not appropriate for all families or all paediatric diabetes centres. The feasibility of home management depends partly upon the geographical area covered by a service. The Cardiff service covers a relatively compact area where the furthest point for a home visit involves a round trip of approximately 48 miles. It is probable that home management would not be a viable, cost or time-effective option for paediatric diabetes centres that cover large rural geographical areas.

Home management is often undertaken by PDSNs who work flexible hours, a necessary characteristic because children are often diagnosed out of office hours. ${ }^{40}$ This has resource implications for staffing, particularly for smaller paediatric centres and district general hospitals, andalthough few centres would advocate a long admission-a short admission may be the most appropriate model for centres with limited nurse resources. Indeed, this model is recommended by some health professionals because of concern about the initial impact of the diagnosis on parents. ${ }^{42}$ Parents of newly diagnosed children, even if they experience an intense emotional response to the diagnosis, have been found to cope successfully when given the opportunity to start treatment at home. ${ }^{23}$ Nevertheless, all relevant factorsincluding psychosocial issues and the family's preferred care environment ${ }^{12}$ - should inform the decision making process at diagnosis.

Ambulatory care has merited little discussion in published reports but could be a viable alternative to home management for some centres. This approach has been successfully adopted since 1996 for families living within reasonable travelling distance of the British Columbia Children's Hospital in Vancouver, Canada. These families attend a diabetes day care programme for approximately four days after diagnosis for education and initial care. ${ }^{43}$ Ambulatory care avoids the need for hospital admission, is cost and timeeffective, and allows a multidisciplinary approach to initial education. Although parents have found the home environment more conducive to learning, ${ }^{28}$ it can be difficult delivering education in a busy household. ${ }^{40}$ Initially, many families prefer a "step by step" approach, and often need their initial education to be reinforced because of poor recall 
following the shock of the diagnosis. ${ }^{23}$ A home visit by the PDSN after completion of the ambulatory care programme would still help ensure that care is tailored to the needs and environment of individual families. This model may also make it easier to support families whose children are started on multiple injection regimens at diagnosis, and probably generates fewer problems when more than one child is diagnosed on the same day. However, ambulatory care does present resource implications for centres such as Cardiff, where there are no dedicated paediatric diabetes day care or clinic facilities.

Home management is more likely to be implemented in the UK when newly diagnosed children are under the care of a specialist paediatric diabetes team and when the appropriate community resources are available; the appointment of a PDSN is often a determining factor for implementation of home management. ${ }^{11}{ }^{12}{ }^{41}$ However, the relative autonomy of the PDSN role can result in feelings of isolation and ultimate responsibility for the welfare of the newly diagnosed child. ${ }^{44}$ Therefore, effective channels of communication between team members are vital. In Cardiff, PDSNs are able to contact medical colleagues at any time for advice about any aspect of diabetes management.

One of the disadvantages of home management concerns the de-skilling of medical and nursing ward staff, who rarely have the opportunity to reinforce their knowledge of the day to day management of diabetes in the ward environment. We have tried to address this in Cardiff with seminars and workshops, and ward based staff are invited to accompany PDSNs on home visits and attend the diabetes clinics. However, workforce mobility and pressure on time makes it difficult to keep all staff updated. This is an important point, as a lack of knowledge and experience in the management of diabetes on the wards could represent an increased clinical risk for children requiring inpatient care in the future. Another disadvantage concerns the potential risk of insulin induced hypoglycaemia. ${ }^{8}$ To avoid this, home managed children in Cardiff are started on an insulin dose of slightly less than $0.5 \mathrm{IU} / \mathrm{kg} / 24 \mathrm{~h}$, this being gradually increased over the first few weeks according to blood glucose concentrations. With this management, none of our home managed children has subsequently experienced severe hypoglycaemia or developed DKA in the early months following diagnosis.

It has been hypothesised that home management conveys the wrong message to families about the seriousness of diabetes $^{45}$; children and their parents may not fully appreciate the severity of the condition because they are not acutely ill at diagnosis and are not admitted to hospital, and this may have an impact on longer term outcomes. Findings from a recent qualitative study suggest that parents of home managed children do recognise the seriousness of diabetes and the importance of optimal glycaemic control, ${ }^{23}$ but further research is required to test this hypothesis.

The need for a telephone on-call system is strongly supported by parents, who report that they feel safer and more able to cope knowing that help is "just a phone call away". ${ }^{23}$ An on-call service has the potential to reduce readmissions or at the very least-as found in Cardiff-to reduce the severity of illness at the time of readmission. However, there are disadvantages to providing this service from a professional standpoint. In Cardiff, the service is available to all families attending our clinic, and 308 out-ofhours calls were received in 2002. It is obvious, therefore, that untimely calls may greatly intrude upon the private lives of team members. Furthermore, paediatric diabetes centres across the UK usually provide this service on a voluntary and unpaid basis. On-call systems should be properly funded and perhaps, to improve efficiency, organised across neighbouring diabetes centres.
The potential benefit of intensive insulin treatment at diagnosis is still being debated. ${ }^{46}$ Early studies found the effect on $\beta$ cell function to be transient ${ }^{47-49}$ but more recent findings suggest that intensive insulin treatment preserves $\beta$ cell function for up to two years post-diagnosis. ${ }^{50}$ There are also suggestions that intensive insulin treatment at diagnosis may reduce the risk for diabetes related complications in later life, ${ }^{22}$ preserve the glucagon response to hypoglycaemia, ${ }^{51}$ and protect against ketoacidosis..$^{52}$ There is currently a lack of evidence to support these claims ${ }^{46}$ and none of the study samples has included children aged 13 years or less. However, if intensive insulin therapy from the time of diagnosis is found to have important advantages, this may have implications for home management owing to the risk of an increased incidence of severe hypoglycaemia. ${ }^{22}$

\section{CONCLUSIONS}

There is insufficient evidence from which to draw conclusions about whether children with diabetes should be managed at home or in hospital from the time of diagnosis. Thus the model of care adopted depends upon various factors such as the clinical condition of the newly diagnosed child, individual family circumstances, and available resources. Home management has been implemented successfully in Cardiff but may not be the most appropriate time and costeffective approach for all paediatric diabetes centres. A short admission may be more appropriate for smaller centres, those with limited staffing, or those covering a large geographical area. Alternatively, ambulatory care may be the way forward for centres with the necessary day care facilities. This review emphasises the need for well designed, prospective, longitudinal studies of hospital and home management from the time of diagnosis which examine children's short and long term physiological and psychological outcomes, cost-effectiveness, and the impact on families. Furthermore, considering the current emphasis on developing health care services in response to the experience of service users, there is a need to examine all approaches to care from the perspective of children with diabetes and their parents.

\section{Authors' affiliations}

L Lowes, Nursing, Health and Social Care Research Centre, Wales, College of Medicine, Cardiff University, Cardiff, Wales, UK

J W Gregory, Department of Child Health, Wales College of Medicine

\section{REFERENCES}

1 Dorman JS, O'Leary LA, Koehler AN. Epidemiology of childhood diabetes. In: Kelnar $\mathrm{CJH}$, eds. Childhood and adolescent diabetes. London: Chapman and Hall Medical, 1995:139-59.

2 Metcalfe MA, Baum JD. Incidence of insulin dependent diabetes in children aged under 15 years in the British Isles during 1988. BMJ 1991;302:443-7.

3 Wadsworth E, Shield J, Hunt L, et al. Insulin dependent diabetes in children under 5: incidence and ascertainment validation for 1992. BMJ 1995;310:700-3.

4 Zhao HX, Stenhouse E, Soper C, et al. Incidence of childhood-onset type 1 diabetes mellitus in Devon and Cornwall, England, 1975-1996. Diabet Med 1999; 16:1030-5.

5 Brink SJ. Presentation and ketoacidosis. In: Kelnar CJH, eds. Childhood and adolescent diabetes. London: Chapman and Hall Medical, 1995:213-40.

6 Schneider AJ. Starting insulin therapy in children with newly diagnosed diabetes. An outpatient approach. Am J Dis Child 1983;137:782-7.

7 Kostraba JN, Gay EC, Rewers M, et al. Increasing trend of outpatient management of children with newly diagnosed IDDM. Colorado IDDM Registry, 1978-1988. Diabetes Care 1992;15:95-100.

8 Lee PDK. An outpatient-focused program for childhood diabetes: design, implementation and effectiveness. Tex Med 1992;88:64-8.

9 McEvilly A. Setting standards for the home care of children with diabetes. Cascade (Action for Sick Children), 1996 December, 4-5.

10 Swift PGF, Hearnshaw JR, Botha JL, et al. A decade of diabetes: keeping children out of hospital. BMJ 1993;307:96-8.

11 Cowan FJ, Warner JT, Lowes L, et al. Auditing paediatric diabetes care and the impact of a specialist nurse trained in paediatric diabetes. Arch Dis Child 1997;77:109-14

12 Matthams D. Diabetes Management: hospital or home. Paediatr Nurs 2003;15:34-6. 
13 Charron-Prochownik D, Maihle T, Siminerio L, et al. Outpatient versus inpatient care of children newly diagnosed with IDDM. Diabetes Care 1997;20:657-60.

14 Hamman RF, Cook M, Keefer $\mathrm{S}$, et al. Medical care patterns at the onset of insulin dependent diabetes mellitus: association with severity and subsequent complications. Diabetes Care 1985;8(suppl 1):94-100.

15 Chase HP, Crews KR, Garg S, et al. Outpatient management vs in-hospital management of children with new-onset diabetes. Clin Pediatr 1992;31:450-6.

16 Laron Z, Galatzer A, Amir S, et al. A multidisciplinary, comprehensive, ambulatory treatment scheme for diabetes mellitus in children. Diabetes Care 1979;2:342-8.

17 Simell T, Putto-Laurila A, Nanto-Salonen K, et al. Randomised prospective trial of ambulatory treatment and one-week hospitalisation of children with newly diagnosed IDDM [abstract]. Diabetes 1995;(suppl 1):594.

18 Spaulding R, Spaulding W. The diabetic day-care unit. II. Comparisons of patients and costs of initiating insulin therapy in the unit and in a hospital. Can Med Assoc J 1976;114:777-9.

19 Banion C, Klingersmith G, Giordano B, et al. Efficacy of outpatient management of new onset diabetes in children [abstract]. Diabetes, 1987;118A(suppl 1)..

20 Strock E, Spencer M, Sandell J, et al. Reimbursement of an ambulatory insulin program [abstract]. Diabetes, 1987;33A(suppl 1).

21 Dougherty GE, Soderstrom L, Schiffrin A. An economic evaluation of home care for children with newly diagnosed diabetes. Results from a randomised control trial. Med Care 1998;36:586-98.

22 Diabetes Control and Complications Trial Research Group. The effect of intensive treatment of diabetes on the development and progression of long term complications in insulin dependent diabetes mellitus. N Engl J Med 1993;329:977-86.

23 Lowes L, Lyne P, Gregory JW. Childhood diabetes: parents' experience of home management and the first year following diagnosis. Diab Med 2004:21:531-8.

24 Coles C. Psychology in diabetes care. Pract Diab Int 1996; 13:55-7.

25 Lowes L, Lyne P. Chronic sorrow in parents of children with newly diagnosed diabetes: a review of the literature and discussion of the implications for nursing practice. J Adv Nurs 2000;32:41-8.

26 Kovacs M, Finkelstein R, Feinberg TL, et al. Initial psychological responses of parents to the diagnosis of insulin dependent diabetes mellitus in their children. Diabetes Care 1985;8:568-75.

27 Koizumi S. Japanese mothers' responses to the diagnosis of childhood diabetes. Int Pediatr Nurs 1992;7:154-60.

28 Hatton DL, Canam C, Thorne S, et al. Parents' perceptions of caring for an infant or toddler with diabetes. J Adv Nurs 1995;22:569-77.

29 Tarnow JD, Tomlinson N. Juvenile diabetes: impact on the child and family. Psychosomatics 1978;19:487-91.

30 Edwards DR. Initial psychosocial impact of insulin dependent diabetes mellitus on the pediatric client and family. Issues in Comprehensive Pediatric Nursing 1987; 10:199-207.

31 Davies AG, Challen AH, Baum JD. Diabetes mellitus. Pediatrician 1988:15:73-9.

32 Simell T, Simell O, Sintonen $\mathrm{H}$. The first two years of type 1 diabetes in children: length of the initial hospital stay affects costs but not effectiveness of care. Diabet Med 1993; 10:855-62.
33 Forsander G. Family attitudes to different management regimens in diabetes mellitus. Pract Diab Int 1995; 12:80-5.

34 Galatzer A, Amir S, Gil R, et al. Crisis intervention program in newly diagnosed diabetic children. Diabetes Care 1982;5:414-19.

35 Strock ES, Sandell JL. A team approach. The ambulatory insulin program: initiating insulin therapy in an outpatient setting, Diabetes Educator 1988; 14:338-45.

36 Lessing DN, Swift PGJ, Metcalfe MA, et al. Newly diagnosed diabetes: a study of parental satisfaction. Arch Dis Child 1992;67:1011-13.

37 British Paediatric Association Working Party. The organisation of services for children with diabetes in the United Kingdom: Report of the British Paediatric Association Working Party. Diabet Med 1990;7:457-64

38 Walker J B. Field work of a diabetic clinic. Lancet, 1953;ii, 445-7.

39 Waine C, Staveley EA. Primary care and the community. In: Kelnar $\mathrm{CJH}$, eds. Childhood and adolescent diabetes. London: Chapman and Hall Medical, 1995:475-81.

40 Lowes L. Measuring effectiveness: the paediatric diabetes specialist nurse role. In: Glasper EA, Ireland L, eds. Evidence-based child health care - challenges for practice. Basingstoke: MacMillan, 2000:285-305.

41 Kirk J, Thomas E, McEvilly A, et al. Extension of a paediatric diabetes home care service. Pract Diab Int 2003:20:125-8.

42 Jefferson I, Kibirige MS. Diabetes - management of the first few weeks. In: Court S, Lamb B, eds. Childhood and adolescent diabetes. Chichester: John Wiley and Sons, 1997:27-40.

43 Vancouver/Richmond Health Board. Your Health. Vancouver Courier 1997:3.

44 Lowes L, Davis R. Ambulatory care of children with newly diagnosed diabetes. In: Glasper EA, Lowson S, eds. Innovations in paediatric ambulatory care. A nursing perspective. Basingstoke: MacMillan, 1998:212-27.

45 Scott A, Donnelly R. Improving outcomes for young people with diabetes: use of new technology and a skills-based training approach is urgently needed. Diabet Med $2001 ; 18: 861-3$

46 Fowler PD, Page SR. Starting insulin in patients with type 1 diabetes mellitus: is there a consensus? Pract Diab Int 2000;17:118-22.

47 Madsbad S, Krarup T, Faber OK, et al. The transient effect of strict glycemic control on B cell function in newly diagnosed type 1 (insulin dependent) diabetic patients. Diabetologia 1982;22:16-20.

48 Perlman K, Ehrlich RM, Filler RM, et al. Sustained normoglycaemia in newly diagnosed type 1 diabetic subjects: short term effects and one year follow-up. Diabetes 1984;33:995-1001.

49 Krarup T, Madsbad S. Effect of two periods with intensified insulin treatment on $\beta$-cell function during the first 18 months of type 1 (insulin dependent) diabetes mellitus. Diab Metab 1986; 12:256-60.

50 Montanya E, Fernandez-Castaner M, Soler J. Improved metabolic control preserved beta-cell function two years after diagnosis of insulin dependent diabetes mellitus. Diab Metab 1997;23:314-19.

51 Pampanelli S, Lepore M, Fanelli C, et al. Intensive treatment maintains normal glucagon response to hypoglycemia in short-term IDDM [abstract]. Diabetologia. 1998:41: A68 (261), (suppl 1).

52 Madsbad S, Alberti KGMM, Binder C, et al. Role of residual insulin secretion in protecting against ketoacidosis in insulin-dependent diabetes. BMJ 1979;ii:1257-9.

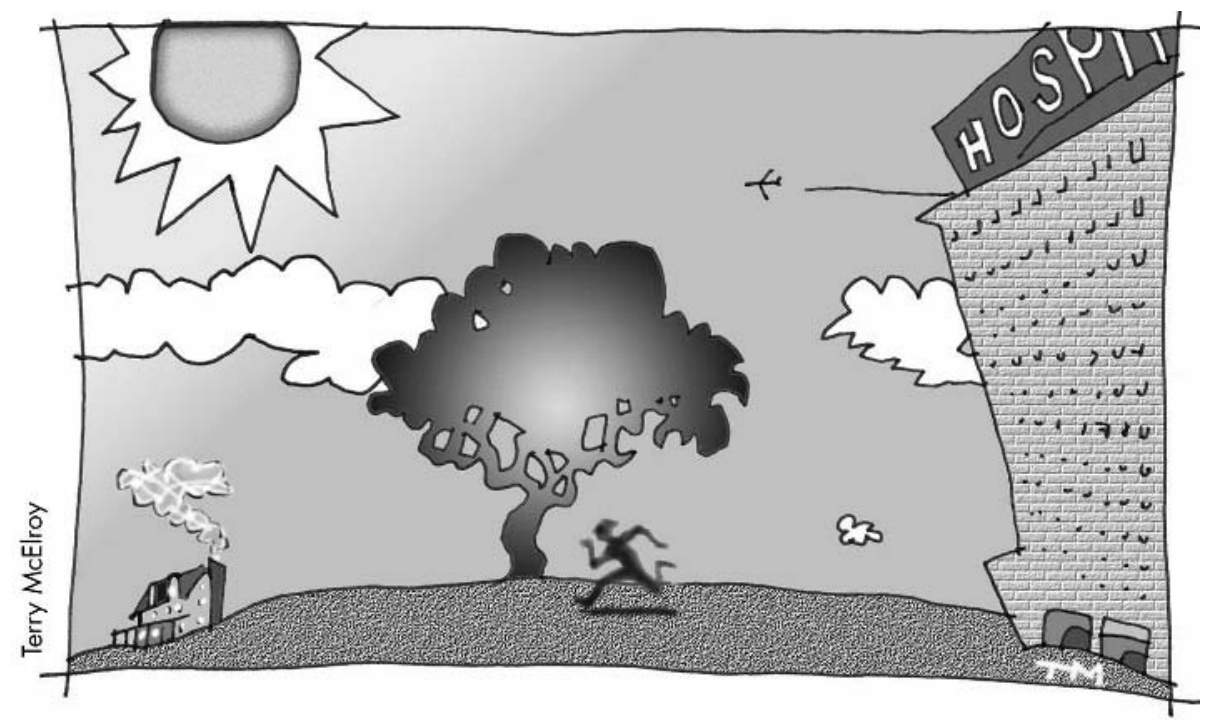

